\title{
El aprendizaje de Rafael Puyana con Wanda Landowska en Lakeville (Connecticut)
}

\author{
Rafael Puyana's Studies with Wanda \\ Landowska in Lakeville (Connecticut)
}

La Fundación Archivo Manuel de Falla (Granada) incorporó en 2013 el legado del clavecinista Rafael Puyana (1913-1931). Si bien es conocida su faceta como intérprete, pocos datos se saben de la formación que recibió antes de su debut y consolidación artística, en concreto del período en el que estudió con Wanda Landowska en Lakeville (Connecticut). Es por ello que es necesaria una aproximación al conocimiento que la clavecinista polaca le transmitió y la manera en que lo hizo, al igual que la ayuda que prestó al joven intérprete para darse a conocer en las salas de concierto. El presente trabajo se fundamenta en una investigación de tipo documental, a partir del vaciado y análisis sistemático de fuentes musicales encontradas en su biblioteca personal, donde se ha trabajado con un importante corpus de correspondencia y programas de concierto, que han sido complementadas con información de otros fondos.

Palabras clave: Rafael Puyana, Wanda Landowska, enseñanza-aprendizaje, conciertos, clave.

In 2013, the Fundación Archivo Manuel de Falla (Granada, Spain) acquired the private library of the harpsichordist Rafael Puyana (1913-1931). Despite his well-known facet as performer, little is known about the training he received prior to making his debut and consolidating his artistic career, in particular the period he studied with Wanda Landowska in Lakeville (Connecticut). A study of the knowledge the Polish harpsichordist passed on to him, and the manner in which she did so, is thus necessary, as is the assistance she gave the young performer in making a name for himself in the concert hall. This article is based on documentary research, the result of combing through and systematically analysing the musical sources found in his private library, and sifting through a substantial amount of correspondence and concert programs. This has been complemented with information gathered from other collections.

Keywords: Rafael Puyana, Wanda Landowska, teaching-learning, concerts, harpsichord.

Las inquietudes de la conocida clavecinista polaca Wanda Landowska (1879-1959) por recuperar el clavecín - tras haber quedado desplazado por el piano en el Romanticismo- e interpretar las obras originalmente escritas para este instrumento se vieron materializadas cuando mandó construir uno -bajo su supervisión y con ayuda de un ingeniero- a la fábrica parisiense de pianos Pleyel. 
Sin duda alguna, el clave le posibilitó profundizar en su labor investigadora e interpretativa, convirtiéndose en la mayor experta. Asimismo, dicho instrumento le sirvió para llevar a cabo su labor pedagógica desde su propia casa ubicada en Saint Leu-la-Fôret (Francia), lugar que tuvo que abandonar por la llegada de la II Guerra Mundial y la invasión alemana, dejando atrás su valiosa biblioteca y colección de instrumentos, cuando tuvo que marcharse a Lakeville (Connecticut, Estados Unidos). Lo que en principio sería una residencia temporal, se convirtió en definitiva y permaneció allí hasta su muerte en 1959.

Precisamente fue en este último lugar donde Rafael Puyana, pianista de formación, recibió durante ocho años las enseñanzas de clave por parte de esta gran amante de la música antigua. El vacío de información existente sobre cómo se inició y desarrolló este aprendizaje hasta que el músico despegó su carrera en solitario hace necesario documentar este período, tomando como referencia el material hallado en el fondo personal del intérprete -donado a la Fundación Archivo Manuel de Falla tras su muerte en 2013-, los documentos de la Biblioteca Nacional de Francia y la Biblioteca del congreso de Estados Unidos, así como distintos diarios consultados. Esto ayudará a comprender cuál fue la herencia musical que Puyana recibió por parte de la clavecinista polaca y cómo se la transmitió a sus discípulos.

\section{La unión de dos artistas}

Las vidas de Wanda Landowska y Rafael Puyana se unieron en el año $1950^{1}$. Para esbozar la historia común de ambos clavecinistas es necesario remontarse unos años atrás y contextualizar qué actividades desarrollaron y qué circunstancias los aunaron.

Por un lado, Landowska era una reconocida intérprete de piano y clave, musicóloga y compositora ansiosa por conocer con profundidad los instrumentos y obras de siglos pasados. Estaba muy ligada a la educación ya que, además de ser una fuente de ingresos, era un medio de expresión y una forma de transmitir "los resultados de su investigación y experiencia"2 que había ido adquiriendo en los numerosos viajes que realizó, donde visitó bibliotecas y

\footnotetext{
${ }^{1}$ Rafael Puyana: Wanda Landowska, pp. 56-58. Recorte de prensa sin referencias de lugar ni fecha de publicación, Archivo Manuel de Falla (en adelante (AMF), Archivo Personal de Rafael Puyana, caja 95. "Cuando yo encontré a Wanda Landowska, ella tenía ya 73 años, pero conservaba, a pesar de la edad, una energía, claridad de pensamiento y una capacidad de análisis sorprendentes. [...]". Véanse también las publicaciones sobre Landowska surgidas al abrigo del centenario de Musique Ancienne: Jean Jacques Eigeldinger (dir.): Wanda Landowska et la Renaissance de la Musique Ancienne, Actes Sud, 2011. Martin Elste: Die Dame mit dem Cembalo, Schott Verlag, Mainz, 2010. Prólogo escrito por Puyana.

${ }^{2}$ Daniel Marty: "Deux claviers pour Jean-Sebastien Bach", Une dame Nommee Wanda, Mairie de SaintLeu-la-Fôret, [s.a], p. 11.
} 
museos que le guiaron en su deseo de conocer y profundizar en las posibilidades técnicas de los instrumentos de teclado ${ }^{3}$. Pese a haber tenido un numeroso alumnado a lo largo de su vida, sobre todo en Saint-Leu-la-Fôret, fue durante la última etapa en Lakeville donde recibió a su último discípulo: Rafael Antonio Lázaro Puyana Michelsen (Bogotá, 14-3-1931; París, 1-3-2013) ${ }^{4}$.

Puyana fue un intérprete de clave colombiano que tuvo una proyección nacional e internacional reconocida de manera unánime por la crítica, quien llegó a calificarlo como el "príncipe de los virtuosos del clavicémbalo" ${ }^{2}$. Nació en el seno de una familia de clase alta y, a la edad de seis años, recibió sus primeras lecciones de piano de la mano de su tía Blanca Michelsen ${ }^{6}$. Esta formación inicial se completó con visitas a las iglesias coloniales y diversas librerías que realizaba con su abuelo materno. Apenas tenía ocho años el día que lo acompañó a una tienda que vendía ejemplares antiguos. Un libro en cuestión - que llevaba por título Wanda Landowska y el espíritu de Saint-Leu-la-Forêt- llamó la atención del joven.Viendo el interés que su nieto había manifestado por aquella publicación, Ernesto Michelsen no dudó en comprárselo ${ }^{7}$.

Pese a que Rafael Puyana se sintió atraído por el clave -que consideraba "un instrumento fascinante" vecinista polaca había construido en Francia', continuó sus estudios pianísticos bajo la dirección del profesor italiano Giacomo Marcenaro ${ }^{10}$ al mismo tiempo que completó su formación en el Liceo de Cervantes y en el Colegio San Bartolomé de su ciudad nata ${ }^{11}$. El músico siempre recordaba la emoción que sintió la primera vez que escuchó la interpretación de Wanda Landowska del Concierto en Re mayor de Haydn cuando aún estaba en la escuela ${ }^{12}$.

${ }^{3}$ Ruggero Gerlin: "L' Ecole de Saint-Leu-la-Forèt", Revue Musicale de Suisse Romande, 32, 3, 1979, pp. 16-17.

${ }^{4}$ Daniel Marty, Eryck de Rubercy: "Le témoignage de Rafael Puyana", Cahiers Wanda Landowska, 3 , Saint-Leu-la-Forêt, France, 1982, pp. 2-7.

5 "En pos de la perfección: Rafael Puyana", Diners, 4-3-2013 (https://bit.ly/2JnRYjn, consulta 5-10-2017).

${ }^{6}$ Johan Pinilla: "Rafael Puyana Michelsen; uno de los grandes intérpretes del clavecín y un virtuoso de la música barroca. Homenaje a su memoria”, Música Antigua, 19-7-2013 (https://bit.ly/2sFMZjq, consulta 22-9-2017).

${ }^{7}$ A. Hudman Cash: Wanda Landowska and the Revival of the Harpsichord: A Reassessment, tesis doctoral, Ed. sur microfilm, Ann Arbor, UMI, 1990, p. 176.

${ }^{8}$ Casimir Ducados: "Rafael Puyana: Elegí el clave porque es un instrumento fascinante", Patria, 28-61972, p. 4.

${ }^{9}$ Se empleará el término clave según la terminología que aporta el artículo de Edwin Ripin et al: "Harpshicord", Grove Music Online, Oxford University Press, 2001.

${ }^{10}$ Críticas de concierto, 16-10-1956, Teatro Colón (Bogotá) de Rafael Puyana, AMF, Archivo Personal Rafael Puyana, caja 100. Prensa. Sobre 7, (https://bit.ly/2kL6Eeh, consulta 5-10-2017).

${ }^{11}$ Juan Carlos Piedrahita: "Cerebro musical fugado", El Espectador, 1-3-2013 (https://bit.ly/2Lkuc4X, consulta 22-9-2013).

${ }^{12}$ D. Marty, E. de Rubercy: "Le témoignage de Rafael Puyana...", p. 2. 
Sus inquietudes musicales le hicieron desplazarse a Boston (Estados Unidos) en 1949 para continuar su formación pianística en el New England Conservatory. Allí estudió la especialidad de piano con Margaret Mason $^{13}$, quien rápidamente se percató de las habilidades musicales del joven intérprete que destacaba entre sus compañeros por sus interpretaciones de J. S. Bach al piano ${ }^{14}$. Como afirma Alice Hudnall en su tesis doctoral, Puyana demostró su deseo de conocer música y músicos asistiendo a los recitales que se programaban en el Conservatorio de Boston. Uno en cuestión, del que apenas se conoce testimonio, marcó un cambio decisivo en su vida al presenciar el concierto de piano y clave interpretado por Wanda Landowska, una experiencia que el músico mantuvo presente en su memoria. Tal fue el impacto y pasión que despertó el clave en él, que el joven decidió dedicar su vida a este instrumento ${ }^{15}$.

Rafael Puyana transmitió sus inquietudes a Margaret Mason, quien desde el primer momento estuvo decidida a apoyar a su alumno para alcanzar sus objetivos: estudiar con Landowska y convertirse en un gran intérprete de clave. Mason lo preparó para la audición que realizaría en Lakeville y serviría como carta de presentación ${ }^{16}$. Además, el intérprete tuvo la suerte de que unos amigos de la familia que conocían a la célebre clavecinista, pudiesen hablarle de é $1^{17}$. Por su parte, el joven músico escribió una carta a Landowska el 21 de febrero de 1950 para concertar un encuentro. A principios del mes siguiente llegaba la respuesta -escrita por Denise Restout, secretaria de la clavecinista-, donde lo citaban el 16 de marzo de ese mismo año:

Estimado Sr. Puyana:

Landowska desea agradecerle su carta del 21 de febrero. Se alegrará de verle y trabajar con usted aquí en Lakeville el jueves 16 de marzo. ¿Va a venir en tren o en coche? ¿Le importaría llamarme el próximo lunes o martes (preferiblemente por la noche) para

${ }^{13}$ Carta de Ernesto Puyana Uscategui a señores del Instituto Interamericano de Musicología, Montevideo, 3-3-1972.

${ }^{14}$ D. Marty, E. de Rubercy: "Le témoignage de Rafael Puyana...", p. 2.

${ }^{15}$ A. Hudman Cash: Wanda Landowska and the Revival..., p. 176. "[...] he came to the United States to study at the Boston Conservatory. There, for the first time, he had the opportunity to hear Landowska play one of her famous piano and harpsichord recitals. He was so overwhelmed by her presence that he knew that he must go to Lakeville and study harpsichord with her [...]".

${ }^{16}$ Carta de Ernesto Puyana Uscategui a señores del Instituto Interamericano de Musicología, Montevideo, 23-3-1972; D. Marty, E. de Rubercy: "Le témoignage de Rafael Puyana...", p. 3.

17 "[...] Ayant échoué dans cette tentative, car il y avait des ordres très stricts de ne laisser passer personne, j'ai eu l'occasion de me faire introduire auprès d'elle par des amis de ma famille qui l'avaient connue lors de ses concerts à Prague avant la guerre. Le contact a été fait et j'avais une réponse à ma lettre me fixant une date pour être reçu et entendu chez elle, je n'avais qu'un désir, et c'était de devenir claveciniste", D. Marty, E. de Rubercy: "Le témoignage de Rafael Puyana...", p. 2. 
avisarme si el 16 de marzo es conveniente para usted y a qué hora podría llegar a Lakeville? [...] Esperando noticias suyas pronto, atentamente, Denise Restout, secretaria ${ }^{18}$.

La formación de Rafael Puyana con Wanda Landowska, como se ha constatado en la correspondencia anteriormente citada y en el programa de mano que se divulgó en el recital que tuvo lugar el 23 de octubre de 1958 en Berlín ${ }^{19}$, comenzó en 1950 -y no en 1951 como apuntan casi todas las biografias-y se extendió hasta prácticamente un año antes de la muerte de la clavecinista en $1959^{20}$.

Se ha de precisar que durante el último período de enseñanza de Landowska, la clavecinista únicamente admitió a un seleccionado alumnado, ya que desconfiaba de los que querían dar unas clases con ella y utilizar su nombre ${ }^{21}$. Entre ellos se encontraban Rafael Puyana y Marie Zorn, quienes llegaron en 1950 y 1956 respectivamente ${ }^{22}$. Además, y como evocaba Genoveva Gálvez -clavecinista española y amiga de Puyana- el intérprete colombiano siempre se complacía en decir que fue muy afortunado en ser el último discípulo en recibir la formación más larga ${ }^{23}$.

\section{La llegada de Rafael Puyana a Lakeville y aprendizaje con Landowska}

El músico colombiano se trasladó a Lakeville y de forma temblorosa llamó a la puerta ${ }^{24}$. Fue recibido por Elsa Schünicke -compañera, secretaria y amiga de la intérprete durante cuarenta y seis años-y más tarde por Denise Restout - asistente de la clavecinista ${ }^{25}$ - quienes estuvieron conversando con él mientras la maestra llegaba ${ }^{26}$. El impacto de esta primera visita fue tal que, todavía

\footnotetext{
${ }^{18}$ Carta de Denise Restout a Rafael Puyana, Lakeville, 9-3-1950. "Dear Mr. Puyana: Madame Landowska wishes me to thank you for your letter of February 21. She will be glad to see you and work with you here in Lakeville on Thursday March $16^{\text {th }}$. Are you coming by train or by car? Would you please phone me next Monday or Tuesday (preferably in the evening) to let me know if March the 16th is convenient for you and at what time you could arrive in Lakeville. [...]. Looking forward to meeting you soon, I am, Sincerely yours, Denise Restout, Secretary".

19 "[...] Seit 1950 arbeitete er Künstlerisch zusammen mit Wanda Landowska. [...]". Programa de mano, Opielt international Barock-Music, Berlin, 23-10-1958, Library of Congress, box 86, folder 1.

20 "Rafael Puyana. Obituary", The Guardian, 9-3-2013 (https://bit.ly/2Jsgpfu, consulta 30-1-2017).

${ }^{21}$ D. Marty, E. de Rubercy: "Le témoignage de Rafael Puyana...", p. 5.

22 A. Hudman Cash: Wanda Landowska and the Revival..., pp. 219-220.

${ }^{23}$ Entrevista realizada por M. Victoria Arjona a Genoveva Gálvez (Granada, España, 10-10-2016).

24 "A première vue, Lakeville me parût charmant, mais quand j'approchais de la propriété où habitait Mme Landowska, j'aperçus sur une colline une veille maison victorienne en bois, grande et for laide. [...]. Je suis monté et j’ai sonné en tremblant". D. Marty, E. de Rubercy: "Le témoignage de Rafael Puyana...", p. 5.

${ }^{25}$ Denise Restout: "Mamusia: Vignettes of Wanda Landowska. Recollections of the late great artist by a devoted companion of many years", High Fidelity, 10, 10, 1960, p. 43.

26 "[...] Nevertheless, he climbed its stairs and with trembling hands rang the door-bell. He was met by Elsa Schunicke and gently led into the living room to wait for Landowska. [...]". A. Hudman Cash: Wanda Landowska and the Revival..., p. 177. Véase también D. Marty, E. de Rubercy: "Le témoignage de Rafael Puyana...", p. 3.
} 
muchos años después, el intérprete podía recordar incluso el atuendo y apariencia fisica de la clavecinista polaca ${ }^{27}$.

Llegó el momento en el que Landowksa le pidió que tocase para ella. La pieza que Rafael Puyana había escogido era la Partita en Do menor de J. S. Bach. El joven intérprete llegó a reconocer, como confirmó Luisa Morales a la autora de este artículo, el miedo que sintió por la buena impresión que quería causarle. Una vez que había preparado los registros y pedales del instrumento, se dispuso a tocar con decisión, pero desgraciadamente se encontró con un clave mudo puesto que los pedales con el que había ensayado en Boston y el Pleyel -superviviente del saqueo musical que hicieron los nazis en la extensa colección musical que la clavecinista tenía en Saint Leu-la-Fôret- operaban en sentido inverso. Una situación que el intérprete siempre lamentó por no tener un comienzo como él esperaba ${ }^{28}$.

Las clases no empezaron hasta transcurridos unos meses del primer encuentro. Por una carta conservada en su fondo personal, se conoce que Rafael Puyana reservó una habitación en un hostal cerca de la residencia de la clavecinista polaca, para permanecer unas cinco o seis semanas desde el 19 de junio de $1950^{29}$.

Aunque en un principio el joven intérprete se desplazó de forma temporal mientras cursaba sus estudios en el New England Conservatory (Boston), pronto se apresuró a realizar todos los trámites para dejar el conservatorio e instalarse definitivamente en Lakeville. Una decisión que inicialmente le generó ciertas dudas ${ }^{30}$.

Las lecciones comenzaron con el análisis de tres o cuatro compases de un pequeño Preludio de J. S. Bach (1685-1750) cuyo título se desconoce. Puyana recordaba cómo Landowska hizo mucho énfasis en "la posición correcta de la mano sobre el clave, el autoconocimiento de la debilidad de los dedos sobre los que faltaba independencia y coordinación" 31 , ya que "su pupilo tenía unas

${ }^{27}$ A. Hudman Cash: Wanda Landowska and the Revival..., p. 177. Hudman tuvo la oportunidad de realizar el 5 de julio de 1987 una entrevista al intérprete colombiano en su apartamento parisino donde el músico le habló del aprendizaje con Landowska. Aunque no hay transcripción, la musicóloga remite a la entrevista que aquí venimos referenciando: D. Marty, E. de Rubercy: "Le témoignage de Rafael Puyana...", p. 4.

${ }^{28}$ Entrevista vía Skype realizada por M. Victoria Arjona a Luisa Morales (Melbourne, Australia 3-82017). D. Marty, E. de Rubercy: "Le témoignage de Rafael Puyana...", p. 4. Véase también A. Hudman Cash: Wanda Landowska and the Revival..., p. 178.

${ }^{29}$ Carta de Thomas W. Colley a Rafael Puyana, Lakeville, 8-6-1950.

30 "He made all the necessary arrangements to leave the conservatory and actually moved to Lakeville, but claims that he was terribly nervous and unsure of whether or not he had made the right decision". A. Hudman Cash: Wanda Landowska and the Revival..., p. 176.

31 "D. Marty: Maintenant dites-vous comment s'est organisé ensuite l'enseignement qu'elle vous a dispensé pendant huit ans. R.Puyana: Les premières leçons n'eurent lieu qu'un mois après. Elles ont commencé par l'étude détaillée d'un petit prélude de Bach, épluché avec minutie. Le temps d'une leçon suffisait à peine pour l'analyse de trois ou quatre mesures, découvrant ainsi à quel point on était ignorant et peu subtil. Cette analyse approfondie orientait les leçon vers les considérations techniques de base: la bonne position de la main sur le clavier, la découverte des faiblesses des doigts, leur manque d'indépendance et de coordination. Landowska s'apercevait de tout et ne laissait rien passer. Je ne crois pas, comme certains l'on dit, que cette 
manos débiles y unos dedos retorcidos" que debía ejercitar y, sobre todo, tener paciencia para llegar a alcanzar su propósito ${ }^{32}$. Eso obligó al joven intérprete a revisar los conceptos y su método de aprendizaje:

Wanda Landowska me enseñó la modestia y me mostró que el camino por el cual avanzaba era un callejón sin salida. Esto me produjo un choque aterrador, obligándome a volver a aprender, a discutir las diferentes concepciones de la posición de las manos y a hacer frente a las debilidades físicas de ciertos dedos. Me ayudó a construir una mano sólida, con dedos independientes y suficientemente fuertes, para nunca compensar esa debilidad con el peso del brazo o del cuerpo. Landowska decía: "Los dedos son soldados comandados por un general, que es la cabeza" y para fortalecerlos había enfocado una gimnasia muy variada. Los estudiantes, que habían trabajado con ella antes de la guerra, pasaban un mes entero haciendo únicamente ejercicios. En mi caso, este entretenimiento duró largo tiempo, pero lo combinó con un trabajo musical que me permitía constatar los beneficios de la técnica que estaba adquiriendo. [...] Su enseñanza nunca me aprisionó, por el contrario me empujaba más bien a crear y encontrarme a mí mis$\mathrm{mo}[\ldots]^{33}$.

Durante su estancia en Lakeville, donde llegó a vivir más de seis años ${ }^{34}$, el intérprete profundizó en "sus estudios de piano y clavicémbalo" con Landowska ${ }^{35}$ al mismo tiempo que completó sus cursos académicos en la Hartt Musical Foundation en Hartford (Connecticut) ${ }^{36}$.

Resulta muy difícil reconstruir los acontecimientos que se desarrollaron durante este período formativo debido a que la información hallada en su documentación personal está incompleta y fragmentada. Tan solo se

attitude stricte servait une intention de réduire et dominer ceux qui cherchaient son aide. Pour arriver à cette conclusion il aurait fallu être insensible à la profondeur de sa pensée, à l'intelligence de son pouvoir d'analyse, à son souci de la perfection et de l'intégrité, ainsi qu'à l'affection et l'enthousiasme qu'elle portait à chaque détail. Quand Wanda se mettait au clavier on s'apercevait de suite qu'elle n'exigeait d'un élève qu'une minime partie de ce qu'elle s'exigeait elle-même". D. Marty, E. de Rubercy: "Le témoignage de Rafael Puyana...", p. 4.

32 "En somme j'étais réduit au niveau d’un débutant. J'en étais bouleversé. Je ne voyais pas comment je pouvais trouver en moi-même le courage nécessaire d'envisager une révision aussi totale de mon art et en somme de ma vie, et comme je lui demandais quel temps il me faudrait pour cela, elle m'a répondu qu'une patience énorme serait indispensable: "Vous voyez bien que vous avez des mains qui ont des faiblesses, certains doits tordus...". Or mes mains n'étaient pas anormales du tout [...]. Aucune attention n'est vraiment portée en profondeur à vos lacunes, surtout aux faiblesses de vos mains et en somme on laisse les gens boiter toute leur vie. Pour une jeune personne, c'est un bonheur exceptionnel de se trouver devant la recherche d'une perfection telle que Landowska l'entendait. Lorsqu'elle posait sa main sur le clavier, cela portait une norme magique, comme mille ans de travail, de contrôle et une grande beauté sonore et formelle". Ibidem, p. 5.

${ }^{33}$ Rafael Puyana: Wanda Landowska..., p. 56.

${ }^{34}$ D. Marty, E. de Rubercy: "Le témoignage de Rafael Puyana...", p. 6.

${ }^{35}$ En la entrevista que le realicé a su discípulo Álvaro Huertas, este mencionó que Puyana permaneció en Lakeville para preparar su debut en el Town Hall de Nueva York el 8-4-1957. Entrevista vía Skype realizada por M. Victoria Arjona a Álvaro Huertas, Bogotá (Colombia), 3-8-2017.

${ }^{36}$ A día de hoy se desconoce el período que Rafael Puyana estuvo en la Hartt Musical Foundation (Hartford, Connecticut) pero sí, que finalizó sus estudios en 1954. 
conservan algunos escritos y escasas partituras, como se muestra en la siguiente tabla, que desvelan las obras que maestra y discípulo trabajaron conjuntamente:

\begin{tabular}{|l|c|}
\multicolumn{1}{|c|}{\begin{tabular}{c}
\multicolumn{1}{|c|}{ Partituras } \\
\multicolumn{1}{|c|}{ AMF. Fondo Personal de Rafael Puyana }
\end{tabular}} & Signatura \\
\hline Johann Sebastian Bach: Praeludium XIV. [Partitura], [Offenbach], Steingräber, [s.a]. & sig. C. 37-1544 \\
\hline $\begin{array}{l}\text { Joseph Haydn: Cadenzas: for the keyboard concerto in D major, opus 21: first and } \\
\text { second movements. [Partitura], New York, Broude Brothers, 1960. }\end{array}$ & sig. C. 11-3506 \\
\hline $\begin{array}{l}\text { Wolfgang Amadeus Mozart: Cadenzas for the piano sonata in b-flat major, K. } \\
\text { 333. [Partitura], New York, Broude Brothers, 1959. }\end{array}$ & sig. C. 19-1908 \\
\hline $\begin{array}{l}\text { W. Landowska and R. Gerlin excercises for harpsichordists, ejercicios para trinos de R. } \\
\text { P. [S.l.]: [s.n.], [s.a]. }\end{array}$ & sig. C. 103-3790 \\
\hline
\end{tabular}

El estudio que se está llevando a cabo del legado de Rafael Puyana deja abierta la posibilidad de encontrar alguna documentación vinculada a este aprendizaje:

Sobre una partitura, Wanda Landowska veía todo y a menudo iba más lejos de lo que el texto indicaba apenas de una manera somera. Ella me enseñó a juzgar, analizar y escoger. En general, muchos alumnos se encuentran frente a profesores que tocan sin poder explicar o analizar lo que hacen. Los alumnos imitan por instinto y quedan satisfechos con explicaciones aproximadas. Ante un problema técnico, Wanda Landowska sabía exactamente dónde estaba la falta y, sobre todo, entendía la causa de la dificultad y cómo remediarla. Ella podía entrar en discusiones sobre lo histórico de las digitaciones, pero si estas no daban buenos resultados, buscaba soluciones prácticas. De sus enseñanzas yo retengo hoy día muchas cosas: el amor por el ritmo, una cierta manera de atacar, la claridad del fraseo, la búsqueda de la belleza sonora sobre cada nota o acorde. Hay muchas cosas que Wanda Landowska sabía y de las que los jóvenes de hoy ni siquiera sospechan su existencia $[\ldots]^{37}$.

Puyana describe la enseñanza con Landowska de una forma lenta y muy detallada. El intérprete recuerda que un día pasaron varias "horas escuchando y juzgando un sonido con diferentes ataques que se podían lograr sobre el clave" 38 . Esto llevó a inquietarlo y a preguntar a su maestra cuánto tiempo

\footnotetext{
${ }^{37}$ Rafael Puyana: Wanda Landowska..., p. 57.

38 "Si son enseignement était un peu paralysant en raison de sa lenteur détaillée, il procédait néanmoins d'une grande sincérité et d'une croyance vitale dans l'opinion esthétique qui l'habitait momentanément. Il fallait énormément de caractère à un élève pour suivre à ce genre d'entraînement. Par exemple, on devait passer des heures à écouter et juger le son des différentes attaques, voire des touches, qu'on pouvait réussir un clavecin. C'est une recherche qui échappe malheureusement aux jeunes clavecinistes d'aujourd'hui. Ils sont gâtés maintenant par des instruments d'une grande beauté sonore de base, ce qui leur est bien commode et ils s'en contentent. Rarement, soupçonnent-ils combien on peut aussi varier et améliorer le son du clavecin classique en formant une riche palette issue de ses propres doigts". D. Marty, E. de Rubercy: "Le témoignage de Rafael Puyana...", pp. 5-6.
} 
tardaría en adquirir esos conocimientos. Esta le respondió que dependería de él. Fue así como el intérprete comprendió que debía trabajar de forma más reflexiva para exprimir una mejor técnica y poder dominar las obras:

Fue un día en el que estaba impaciente por preguntarle sobre cuánto tiempo me llevaría llegar allí: "Bueno será, no sé, cinco años, dependerá de usted, seis años, siete años". Ella me hizo comprender que con su método o cualquier otro que fuese válido, terminaría por entender que el arte no es una cosa ligera y que trabajando de una forma más reflexiva un artista llega a dominar un lenguaje, a formar su propia manera de pensar y desarrollar sus medios técnicos para expresarlos. A partir de ahí, esta enseñanza se convirtió, como le dije, muy lento, muy detallado, en una especie de goteo. Pasó mucho tiempo antes de que tuviera la sensación de dominar una obra en plena visión de su contenido y su gran línea, pero tuve la alegría de sentir que una vez que la dominaba, estaba tocando a un nivel absolutamente superior. No podía escuchar la forma en que otros debían tocar porque todo parecía improvisado en el sentido peyorativo de la palabra, superficial y aparente. Poco a poco fui avanzando hacia una concepción musical basada en la integridad, la reflexión y mi propia convicción ${ }^{39}$.

Durante esta etapa formativa, el músico colombiano preparó con la clavecinista los exámenes del curso académico 1953-1954 en la Hartt School of Music en Hartford. Como dicha institución no tenía clavecín, Landowska invitó a Mosche Paranov (director) y a otros compañeros de la escuela a su casa en Lakeville para dar a conocer a Rafael Puyana como clavecinista. Según informa la carta que la propia clavecinista polaca envió al padre de $\mathrm{Pu}-$ yana, entre las obras que conformaban ese programa se encontraban un Preludio de J. S. Bach, Le Coucou (1735) de L. C. Daquin y la Fantasia de la Partita $n .^{\circ} 3$ en La menor (BWV 827) de J. S. Bach. Sobre todo, esta última pieza fue la que más impresionó a la audiencia allí presente, tanto por la dificultad como por la ejecución que realizó el joven intérprete. Un encuentro muy fructífero en el que el además de ser presentado, Puyana recibió la propuesta del director de la escuela para tocar en su recital de graduación y en los conciertos para clave y piano de J. S. Bach y W. A. Mozart con la orquesta que dirigía en Hartford ${ }^{40}$.

39 "Il fut un jour où j'ai eu limpatience de lui poser la question sur le temps qu'il me faudrait pour y arriver. 'En bien ce sera, je ne sais pas, cinq ans, cela dépendra de vous, six ans, sept ans'. Elle m'a fait comprendre qu'avec sa méthode ou n'importe quelle autre qui serait valable, je finirais par comprendre que l'art n'est pas chose légère et que ce n'est qu'en travaillant de la façon la plus réfléchie qu'un artiste arrive à dominer un langage, à former sa propre façon de penser et développer les moyens techniques permettant de les exprimer. A partir de là, cet enseignement devint, comme je vous l'ai dit, très lent, très détaillé, une sorte de goutte-à-goutte. Beaucoup de temps passa avant d'avoir la sensation de dominer une ceuvre en pleine vision de son contenu et de sa grande ligne, mais j'ai eu la joie de sentir qu'une fois qu'on la maîtrisait c'était avoir touché à un niveau de choses absolument supérieur. Je ne pouvais plus entendre la façon que d'autres avaient de jouer car tout semblait improvisé dans le sens péjoratif du mot, superficiel et apparent. Je m'acheminais petit à petit vers une conception musicale basée sur l'intégrité, la réflexion et ma propre conviction". Ibid., p. 5.

${ }^{40}$ Carta de Wanda Landowska a Ernesto Puyana, Londres, 1-6-1953. 
En el fondo personal del clavecinista tan solo se ha localizado un programa que, a juzgar por la fecha y lugar en que se realizó, parece responder a la primera oferta de Paranov. También se conoce que lo preparó con Landowska y que lejos de interpretarlo en solitario, acompañó con el clave Pleyel al flautista Carl Bergner ${ }^{41}$. Así lo transmitía la maestra polaca a la familia del intérprete:

Me complace decirle que su hijo trabaja con una inteligencia y entusiasmo por su arte que me hace muy feliz. Además, no es de extrañar que su progreso sea extraordinario. Estamos preparando un programa muy bueno para su recital que se celebrará en mayo en Hartford. Tan pronto como este programa esté completamente arreglado, Rafael se lo enviará. Una gran parte estará dedicada a la música española y en particular a Scarlatti. Rafael siente la música de Scarlatti de una manera muy intensa y estoy segura que él tocará muy bien. Parece que, como resultado de una falsa noticia, usted había pensado que Rafael pasaría sus vacaciones en otro lugar. No puedo describirle cuán profundamente se vio afectado por el hecho de que pudiese creer tal cosa. ¿Cómo, si este chico trabaja con un ahínco ejemplar, han sido capaces de creer una historia tan inverosímil? Admito que yo misma estaba muy sorprendida ${ }^{42}$.

Al final de ese curso académico, Rafael Puyana obtuvo su grado de "Bachelor of Music en el Hartt Musical Foundation en Hartford (Connecticut)" "43. Esta no fue la única participación del intérprete en esta institución, ya que como se comprueba en la recopilación de los conciertos ofrecidos a lo largo de su vida, también colaboró durante los dos años siguientes ${ }^{44}$. La maestra explicaba a la familia del joven lo orgullosa que se sentía por los progresos que había conseguido:

Pero lo que me dio la mayor alegría, es darme cuenta de los extraordinarios progresos de Rafael. Ha trabajado con una seriedad, entusiasmo e inteligencia ejemplar. Su técnica y el conocimiento de sus dos teclados y los pedales son destacables. Siempre encontré que la musicalidad y los dones naturales de Rafael eran excepcionales, pero la rapidez con la que sus aptitudes se desarrollan es para mí una alegría.Además, no estoy sorprendida de ver su cultura intelectual enriquecerse, pronóstico de una gran carrera artística. Rafael debe estar junto a usted. Le podrían, si así lo consideran,

${ }^{41}$ Programa de mano, 19-5-1954, Hartt College of Music, Hartford.

${ }^{42}$ Carta de Wanda Landowska, a la familia de Rafael Puyana. 31-12-1953, s.l. "Je suis heureuse de pouvoir vous dire que votre fils travaille avec une intelligence et un enthousiasme pour son art qui me rendent beaucoup de joie. Aussi, il ne faut pas s'étonner que ses progrès soient extraordinaires. Nous préparons un très beau programme pour son récital qui aura lieu en Mai à Hartford. Dès que ce programme sera complètement fixé, Rafael vous l'enverra. Une grande partie sera consacrée à la musique espagnole et en particulier à Scarlatti. Rafael sent la musique de Scarlatti d'une façon très intense et je suis sûre qu'il jouera très bien. Il paraît qu'à la suite d'une fausse nouvelle vous aviez cru que Rafael passerait ses vacances ailleurs. Je ne saurais vous décrire combien il a été profondément affecté que vous ayez pu croire une chose pareille. Comment-alors que ce garçon travaille avec un zèle exemplaire-avez-vous pu ajouter foi à un racontar aussi invraisemblable? J'avoue que moi-même j'en suis restée fort surprise".

${ }^{43}$ Críticas de concierto, 16-10-1956, Teatro Colón (Bogotá) de Rafael Puyana.

${ }^{44}$ Programa de mano, Hartt Musical Foundation, Hartford, 19-5-1955; programa de mano, 15-11956, Hartt Musical Foundation, Hartford; anuncio de concierto, 7-6-1956, Hartt Musical Foundation, Hartford. Rafael Puyana: "Renacimiento del Clavicémbalo", Lecturas Dominicales, Bogotá, 21-10-1956. 
leer esta carta. Pienso en la alegría que le dará rencontrarse los tres. Mis mejores deseos para su encantadora esposa y para usted, estimado señor y amigo, garantía de una amistad cordial ${ }^{45}$.

Del mismo modo, mostraba su orgullo en la evaluación del 20 de enero de 1955, donde otorgó la máxima calificación al joven músico en las lecciones privadas de clave y literatura musical -según los criterios establecidos- y como se puede comprobar en los siguientes documentos:

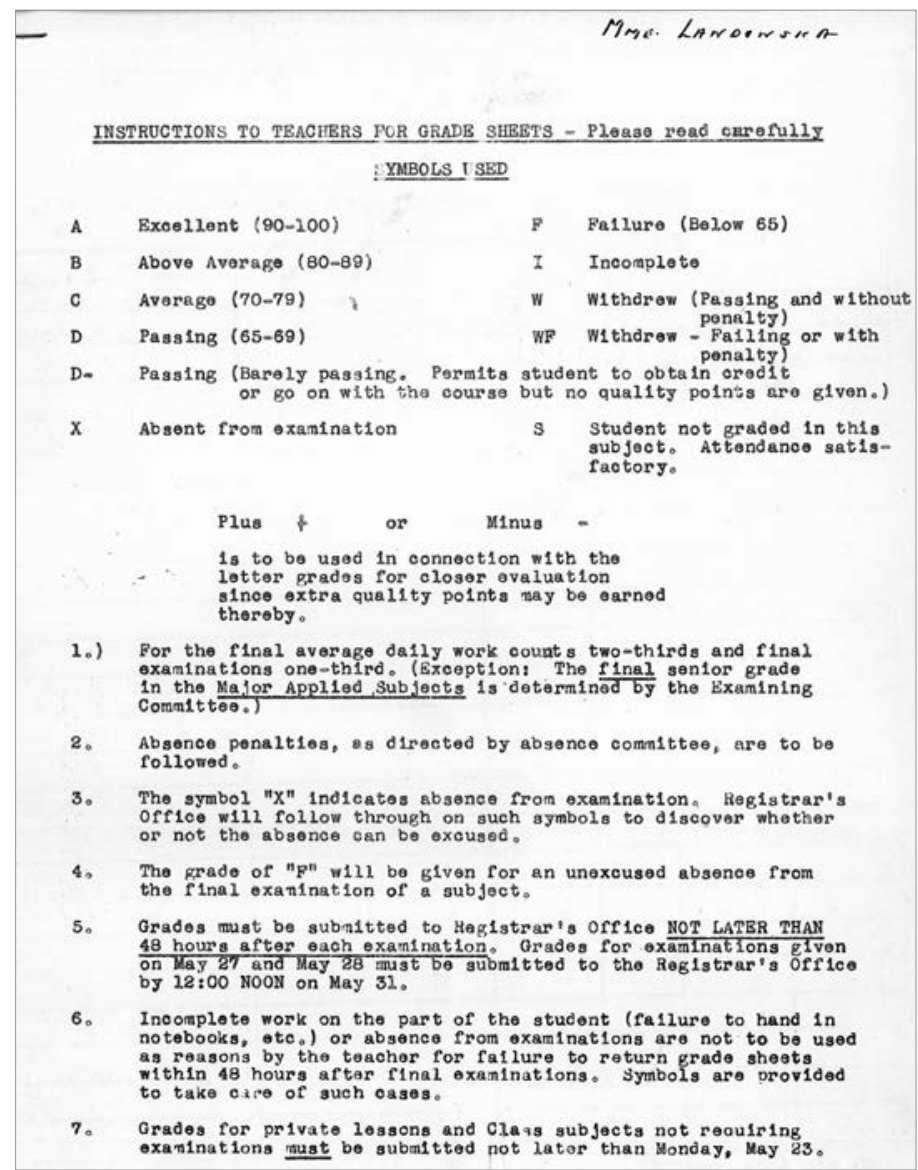

Ilustración 1. Instrucciones de evaluación de Wanda Landowska

${ }^{45}$ Carta de Wanda Landowska a Ernesto Puyana, Londres, 1-6-1953. "Mais ce qui m’a donné la plus grande joie, c'est de constater les progrès immenses de Rafael. Il travaille avec un sérieux, un enthousiasme et une intelligence exemplaires. Sa technique et sa connaissance de ses deux claviers et des pédales sont remarquables. J'ai toujours trouvé que la musicalité et les dons naturels de Rafael étaient exceptionnels, mais la rapidité avec laquelle ses dons se développent est pour moi une joie. Aussi, je ne suis pas surprise 


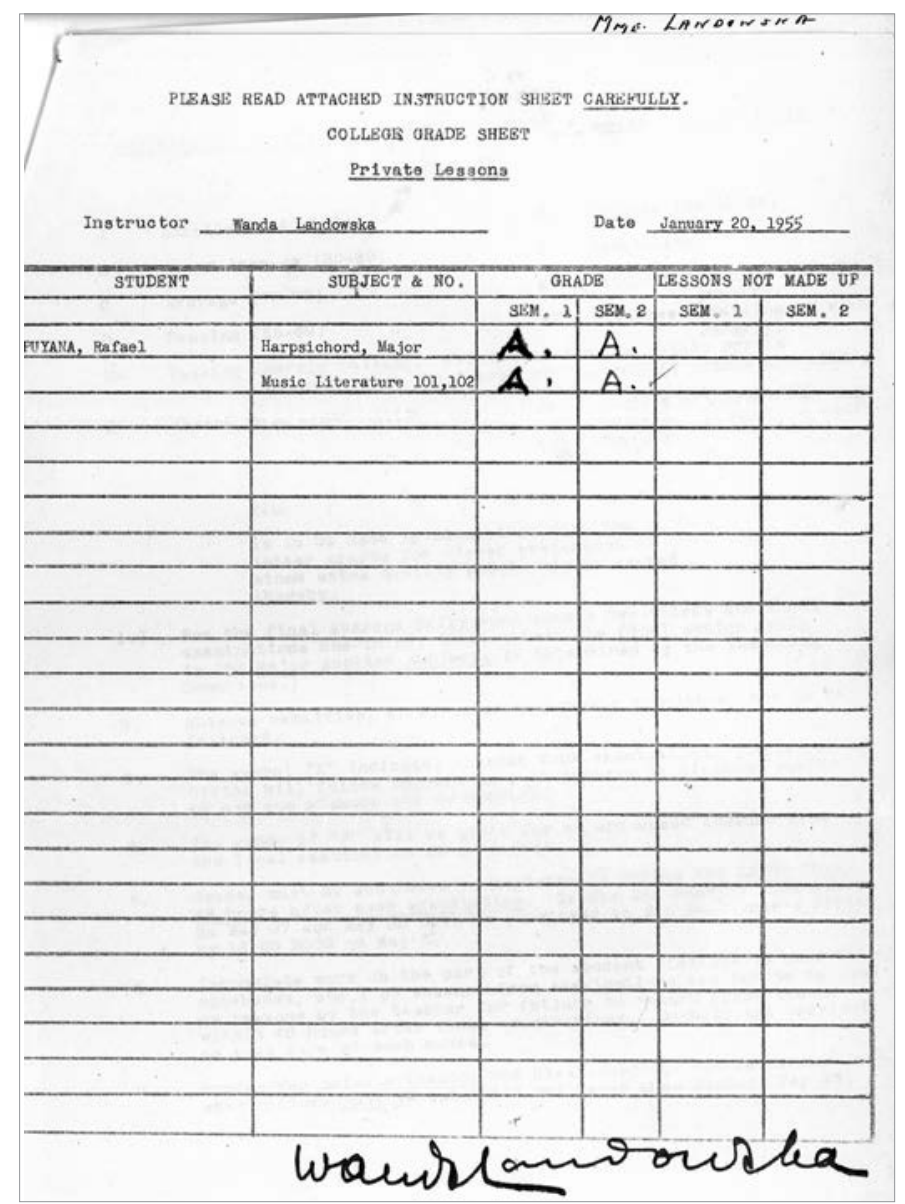

Ilustración 2. Calificación obtenida por Rafael Puyana mientras estudia con Wanda Landowska ${ }^{46}$.

La maestra llegó a reconocer lo exigente que fue con el joven para que trabajase y se implicase aún más, mejorase su técnica y se convirtiese en un gran intérprete, como recordaba Álvaro Huertas ${ }^{47}$. Asimismo, como su discípula

de voir sa culture intellectuelle s'enrichir, pronostic d'une belle carrière artistique. Rafael doit être maintenant auprès de vous. Vous pourriez -si vous le jugez bon- lui lire cette lettre. Je pense à la joie que vous aurez à vous retrouver tous les trois ensemble. Mes meilleures pensées pour votre charmante femme et pour vous, cher Monsieur et Ami, l'assurance de la cordiale amitié".

${ }^{46}$ Todas las imágenes incluidas en este trabajo se encuentran en el AMF, Archivo Personal de Rafael Puyana. Reproducidas con la autorización del AMF.

47 "Pues un día me dijo que Wanda le había dicho 'si usted no se resuelve a tomarse esto en serio, llamo a su padre y le digo que no le doy más clases' y entonces él se ponía a estudiar”. Entrevista vía Skype realizada por M. Victoria Arjona a Álvaro Huertas, Bogotá (Colombia), 3-8-2017. 
Genoveva Gálvez evocaba, esto le supuso un esfuerzo puesto que estuvo mucho tiempo alejado de su familia con la que estaba profundamente unido ${ }^{48} \mathrm{e}$ incluso llegó a pasar alguna que otra Nochebuena en casa de su maestra preparándose para emprender su carrera como clavecinista en solitario:

[...] Lo que me hace muy feliz es que Rafael conoce perfectamente la vida de artista a la que se está preparando. Esta vida es muy hermosa, pero también muy dura. Demanda un trabajo incesante. No se debe olvidar jamás que un artista consigue aplausos y un gran éxito debido a su trabajo. Su hijo trabaja sin descanso, pero le vigilo todo lo que puedo para que no se canse demasiado, que coma bien y que tome el aire. Participo de la felicidad de sus abuelos y espero que me envíen una foto del pequeño Ricardito. ¡Felicidad, salud y feliz año nuevo $!^{49}$.

El intérprete admiraba a Landowska porque era una mujer, que además de dominar el arte, sabía explicarlo. También valoraba su inteligencia y espontaneidad enseñando ${ }^{50}$, ya que prestaba atención a los problemas técnicos particulares que tenía cada alumno/a y le proporcionaba las herramientas necesarias para que tuviese conciencia y trabajase ${ }^{51}$.

Puyana recordaba lo minuciosa y exigente que era la maestra, quien estudiaba profundamente cada detalle de las obras "con una gran paciencia e inteligencia", además de cómo enseñaba la técnica "en función del resultado sonoro" $"$.

Su método iba más allá de corregir los aspectos anteriormente mencionados y estudiar el repertorio ${ }^{53}$, ya que pretendía que su alumnado fuese

48 "Eran tres hermanos. Él de varón único y dos hermanas. Era muy mimado por sus padres. Tenía una veneración por su madre. Físicamente parece que se prestaba a que le arroparan, pero a su vez necesitaba expandirse por su música por Francia. Allí estableció relaciones con otros músicos, literatos, políticos". Entrevista realizada por M. Victoria Arjona a Genoveva Gálvez, Granada (España), 10-10-2016.

49 “[...] Ce qui me fait infiniment plaisir c'est que Rafael soit parfaitement conscient de la vie d'artiste à laquelle il se prépare. Cette vie est très belle mais elle sait être très dure. Elle demande un travail incessant. Il ne faut jamais oublier que si un artiste récolte des applaudissements et un grand succès, c'est dû au travail. Votre fils travaille sans arrêt, mas je veille autant que je le peux à ce qu'il ne se fatigue pas trop, à ce qu'il mange bien et à ce qu'il prenne l'air. J'ai pris part à votre bonheur de grands-parents et j'espère que vous voudrez bien m'envoyer une photo du petit Ricardito. Bonheur, Santé, bonne et joyeuse nouvelle Année!". Carta de Wanda Landowska a la familia de Rafael Puyana, 31-12-1953.

50 "D. Marty: Ça risquait d'être un petit décourageant? R. Puyana: C'était en même temps décourageant et stimulant. Je voyais qu'il y avait quelque chose d'unique à conquérir et valorisait la chance de connaître quelqu'un qui non seulement dominait un grand art, mais savait l'expliquer. Faudrait-il ajouter que Landowska réussissait à être à la fois spontanée et intelligente dans son enseignement [...]”. D. Marty, E. de Rubercy: "Le témoignage de Rafael Puyana...", p. 5.

${ }^{51}$ Denise Restout: "Pour le quatre-vingtième anniversaire de Gusta Goldschmidt", Cahiers Wanda Landowska, Saint-Leu-la-Forêt, France, 12, 1993, p. 6.

52 R. Puyana: Wanda Landowska..., p. 55.

${ }^{53}$ Robert Sabin: "Voyage of Discovery. Wanda Landowska Has Devoted 50 Years to Understanding The Well-Tempered Clavier", Musical America, 15-2-1955, p. 3. 
-al igual que ella- capaz de regular sus instrumentos ${ }^{54}$ y hacer investigaciones musicológicas en las bibliotecas ${ }^{55}$ cuando hacía sus tournées ${ }^{56}$.

En la biblioteca personal del intérprete existen numerosos documentos procedentes de diversas instituciones musicales como la Biblioteca Nacional de Francia ${ }^{57}$, que le sirvieron no solo para conocer aspectos interpretativos, del estilo y estética musical de cada obra que trabajó, sino también para realizar las notas a los programas que acompañaban a sus grabaciones discográficas ${ }^{58}$. Entre esta cuantiosa documentación que alberga el Fondo Puyana, cabe destacar el escrito que el clavecinista hizo en $2006^{59}$ acompañando a uno de sus últimos trabajos discográficos y que apareció un año después junto a la grabación The Musical Sun of Southern Europe publicada por Sanctus Recordings. En ella, empleó el virginal rectangular de Baptista Carenonus (Salò, 1700?), la espineta trapezoidal firmada debajo de una tecla por Fecit Rinaldo Bertoni (Bolonia, 1707) y el clave de Andrés Fernández Santos (Valladolid, 1728) en el primer volumen. Este último instrumento también se utilizó junto al gran pianoforte de Antón Walter (circa 1790-1795) y dos pianofortes de Johann Schantz en el segundo ${ }^{60}$.

Más que un punto de llegada, este artículo es un inicio que arroja luz sobre los comienzos musicales de ambos artistas. En futuras publicaciones, y a partir de sus grabaciones, se analizará la propia práctica interpretativa.

A lo largo de su vida, Puyana puso en práctica toda esta educación recibida y de la misma manera se lo transmitió a sus discípulos:

${ }^{54}$ Denise Restout: "Pour le quatre-vingtième anniversaire...", pp. 6-7.

${ }^{55}$ D. Restout: "En souvenir de Ruggero Gerlin. Lakeville Février 1995", Cahiers Wanda Landowska. Saint-Leu-la-Forêt, France, 13, 1995, p. 3. Cahier Wanda Landowska; R. Sabin: "Voyage of Discovery. Wanda Landowska...", p. 3.

${ }^{56}$ R. Gerlin: "LEcole de Saint-Leu...", pp. 16-17.

${ }^{57}$ Se conoce que Puyana fue usuario de la BNF. Hasta el momento se han localizado dos documentos fechados en diciembre de 1962 que lo acreditan: Un carnet de usuario de Rafael Puyana, 5-12-1962, Bibliothèque nationale de France. BNF, s.n. Véase también el Carnet de usuario de Rafael Puyana, 25-121962, Archivo Personal de Rafael Puyana, caja 66. Adj. 2428.

${ }^{58}$ En el legado se conservan los documentos que el intérprete recopiló, los que solicitó que le enviasen y los que personas allegadas al intérprete le remitieron pensando que podían ser de su interés sobre el arte y la cultura, noticias de actualidad, libros, artículos o fotocopias de textos científicos que le ayudaron a conformar los programas de concierto y notas discográficas.

${ }^{59}$ Se conservan numerosos borradores repartidos entre las cajas 91, 114 y 168 de su fondo personal.

${ }^{60}$ The Musical Sun of Southern Europe. Vol. 1, Fandango and other Spanish and Portuguese Works, Rafael Puyana (clavecín), Sanctus recordings, 2007. The Musical Sun of Southern Europe. Vol. 2. Fandango and other Spanish and Portuguese Works, Rafael Puyana (clavecín), Sanctus recordings, 2007. 


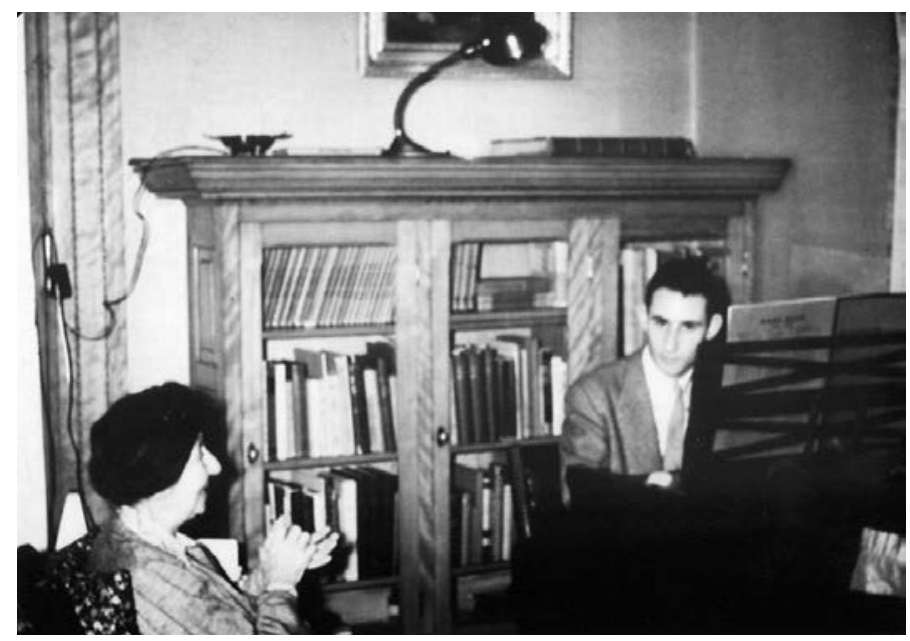

Wanda Landowska y Rafael Puyana en Lakeville

El músico reveló que, durante esta etapa formativa, aprendió tanto de las lecciones recibidas como de los paseos que compartió con su maestra, afirmando que fueron incluso más provechosos que las clases recibidas en las escuelas y conservatorios donde hizo sus estudios:

D. Marty: Además de tus lecciones, ¿̇tuviste la oportunidad de hablar con tu maestra sobre otras materias?

R. Puyana: Sí, la acompañé en los paseos diarios en una pequeña carretera remota, Beldo Road, sobre una colina donde el aire y la vista de la naturaleza le daban fuerza y ganas de tocar el clave, o de grabar hasta altas horas de la mañana. Tenía una conversación animada, muy emotiva, siempre buscando la palabra precisa para expresar la idea que quería comunicarme. A Wanda le gustaba analizar a otros artistas geniales que había conocido, a menudo comentando me hacía comentarios y observaciones de su arte, su personalidad y su lado esencial. Quizás puede que haya aprendido más sobre la elevación del nivel artístico en todos esos paseos que en tantas escuelas y conservatorios donde estudié. ¿Sabe usted, señor Marty, que para convertirse en artista solo hay una forma de aprender y es al lado del que ya lo es? ${ }^{61}$.

${ }^{61}$ D. Marty, E. de Rubercy: "Le témoignage de Rafael Puyana...", p. 6. "D. Marty: En dehors de vos leçons aviez-vous l'opportunité de vous entretenir avec votre Maître sur d'autres sujets que la musique. R. Puyana: Qui, je l'accompagnais dans des promenades jour lanières sur une petite route éloignée Beldo Road au soum met d'une colline où l'air et la vue de la nature lui donnaient force et envie de jouer du clavecin, ou d'enregistrer jusqu'aux petites heures du matin. Elle avait une conversation animée, très émotive, toujours cherchant le mot précis pour exprimer l'idée qu'elle voulait me communiquer. Wanda aimait analyser d'autres artistes de génie qu'elle avait connus, me faisant souvent des commentaires et des observations sur leur art, leur personnalité et leur côté essentiel. J'ai peut-être appris plus de choses sur la hauteur d'un niveau artistique dans ces promenades que dans tant d'écoles et conservatoires où j'ai fait mes 
Esta estancia permitió al joven intérprete entrar en contacto con otros artistas que iban a visitar a la clavecinista, entre los que se encontraban François Poulenc (1899-1963), un compositor que Puyana anhelaba conocer. Para complacer a su alumno, Landowska le envió una carta transmitiéndole los deseos de su discípulo:

Francis querido, mi alumno Rafael Antonio Puyana, excelente clavecinista, un muchacho muy amable, está encantado de conocerte personalmente. Te transmitirá mi afecto. Te abrazo de todo corazón, que languidece de estar lejos de mis seres queridos y de París. Wanda ${ }^{62}$.

También conoció a Genovière Thibault, condesa de Chambure (19021975), quien llegó a convertirse en la conservadora del Museo Instrumental del Conservatorio Superior de Música de París (1961-1973) ${ }^{63}$. Thibault incluso llegó a prestarle al intérprete algunos instrumentos originales históricos cuando residía en París ${ }^{64}$. Además, tuvo la oportunidad de relacionarse con otros artistas e intelectuales como Bernard Gavory, Doda Conrad, Jacques Caroli $^{65}$, Henry-Louis de La Grange ${ }^{66}$ o el crítico musical de la Revue Musical Marc Pincherle.

Al iniciar las clases con Landowska, el intérprete estuvo interesado en adquirir un clave como el de su profesora. Fue así como la clavecinista contactó con Pincherle para solicitar que acompañase al joven músico -cuando se trasladara a París- para comprar un Pleyel:

Querido amigo, Mi alumno, Rafael Puyana, te enviará mis afectuosos pensamientos. Estará contento al comprar un clave Pleyel. Estoy segura de que tendrás la amabilidad de ayudarlo y guiarlo. Pienso en ti muy, muy a menudo, leyendo y

études. Savez-vouz, Monsieur Marty, que pour devenir artiste soi-même il n'y a qu'un seul court chemin apprendre aux côtés de celui qui l'est déjà"; A. Hudman Cash: Wanda Landowska and the Revival..., pp. 177-178.

62 "Francis chéri, Mon élève Rafael Antonio Puyana, excellent claveciniste, très gentil garçon, est heureux à l'idée de vous connaître personnellement. Il vous transmettra mes tendresses. Je vous embrasse de toute mon cœur qui languit d'être loin de mes suis et de Paris. Wanda". Carta de Wanda Landowska a François Poulenc, Lakeville, 1-7-1953, BNF, VM BOB-24168, p. 663.

${ }^{63}$ Georges Henri: La museología. Curso de museología/ Textos y Testimonios, Madrid, Akal, 1993, pp. 148 149.

${ }^{64}$ Entrevista realizada por M. Victoria Arjona a Genoveva Gálvez, Granada (España), 10-10-2016.

65 "D. Marty: Voyait-elle encore des amis très fidèles ? R. Puyana: De temps à autre j'étais invité à prendre le thé ou un repas, quand un de ses amis éuropéens de passage à New York faisait le long parcours jusqu'à Lakeville pour lui rendre visite, Je me souviens d'y avoir connu le grand compositeur Francis Poulenc et la Comtesse de Chambure, plus tard célèbre conservateur du Musée Instrumental du Conservatoire de Paris, ainsi que les critiques, Marc Pincherle, Bernard Gavory et d'autres personalités telles que Doda Conrad, le Professeur Jacques Caroli, etc. Elsa et Denise savaient préparer d'excellents thés et il régnait une ambiance pleine d'esprit". D. Marty, E. de Rubercy: "Le témoignage de Rafael Puyana...", pp. 5-6. Véase también A. Hudman Cash: Wanda Landowska and the Revival..., p. 179.

${ }^{66}$ Carta de Denise Restout a Rafael Puyana, 25-10-1958. 
volviendo a leer tus magníficos libros y estudios. No me olvido de nuestras horas de Lozere, Rue Lapeyrere. ¿Cómo está su esposa? Mi madre la quería muchísimo. Sigo siendo tu fiel amiga. Wanda Landowska ${ }^{67}$.

Este fue el instrumento con el que Puyana realizó sus primeras giras, gracias a lo que fue adquiriendo la popularidad con la que hoy día se conoce. El clave Pleyel de Puyana se encuentra actualmente en la Fundación Archivo Manuel de Falla desde que el intérprete lo donase en 1992. Parece ser que este instrumento, como Denise Restout manifiesta en una de las cartas localizadas, no debió haber salido muy bueno por lo que aconsejó al intérprete escribir a la casa Pleyel para informarle del problema y que en caso de querer comprarse otro, adquiriese el construido por el señor Lebal ${ }^{68}$.

\section{Inicio de una exitosa carrera en solitario}

El hecho de recibir clase de una maestra de renombre fue una buena carta de presentación para el joven músico que pronto empezó a recibir las primeras propuestas de concierto. Entre ellas, se ha de resaltar la de la señora Rose N. Mende, quien le sugirió realizar un recital de clave el día 5 de noviembre de 1953 en The Musical Club de Hartfort:

Mi querido Sr. Puyana. Después de descubrir que eres alumno de la Sra. Landowska y que estás estudiando teoría musical en Hartford, aprovecho esta oportunidad para escribirte y preguntar si considerarías tocar en el Hartford Musical Club en el Hall. Estoy planificando el programa para la temporada de 1953-54, el comité del programa ha decidido que le gustaría usar el clavicémbalo en su programa de apertura, el jueves 5 de noviembre de 1953 por la mañana. Nos gustaría que actuara, si todo esto es posible. Esperaríamos un grupo de solos de clave y también que el instrumento pudiese ser utilizado como instrumento acompañante o en conjunto. Si está interesado, háganos saber cuál es su cargo, para que podamos planificar nuestro presupuesto. Adjunto un sobre con nuestra dirección. ¿Podría responder lo antes posible? Saludos cordiales. Rose N. Mende. Presidenta ${ }^{69}$.

\footnotetext{
67 "Cher Ami, Mon élève, Rafael Puyana, vous transmettra mes affectueuses pensées. Il serait heureux d'acheter un clavecin Pleyel. Je suis sûre que vous aurez la bonté de l'aider et de le guider. Je pense à vous très, très souvent, en lisant et relisant vos magnifiques livres et études. Je n'oublie pas nos heures amicales de Lozère, de la Rue Lapeyrère. Comment va votre femme? Ma mère l'aimait tendrement. Je demeure votre Amie très fidèle. Wanda Landowska". Carta de Wanda Landowska a Marc Pincherle, Lakeville, 6-5-1951.

${ }^{68}$ Carta de Denise Restout a Rafael Puyana, 25-10-1954.

69 "My dear Mr. Puyana. Having discovered that you are a pupil of Madame Landowska and that you are studying music theory in Hartford, I am taking this opportunity of writing to you to ask whether you would consider playing for the Hartford Musical Club in the Hall. I am planning the programme for the 1953-54 season, the program committee has decided that it would like to use the harpsichord on its opening program, Thursday morning, November $5^{\text {th }}, 1953$. We would like to have you perform, if it is at all possible. We would expect a group of harpsichord solos, and we would also like the instrument to be used as an as companying instrument or an ensemble. If you are interested would you please let us know what
} 
El primer programa conservado en su legado está fechado en 1954, por lo que se desconoce si finalmente el intérprete llegó a realizarlo. A pesar de que Rafael Puyana comenzase a ofrecer sus programaciones de concierto en la segunda mitad de los años 50 en Norteamérica, no fue hasta 1957 cuando emprendió las giras por los escenarios internacionales como los de la Hotchkiss School, el Jordan Hall de Boston y sobre todo su triunfo en el Town Hall de Nueva York ${ }^{70}$.

Para la organización de su debut neoyorkino, el intérprete obtuvo la ayuda de su padre, que realizó las gestiones pertinentes para alquilar el establecimiento y vender las entradas. La prensa reconoció la "magnífica interpretación" que el joven llevó a cabo y le auguró un futuro brillante como clavecinista $^{71}$.

Durante este primer impulso y el resto de su carrera, siempre tuvo el apoyo y ánimo de su profesora y de su círculo musical más cercano. Denise Restout $^{72}$ y Elsa Schünicke a menudo le facilitaron las direcciones y los contactos de familiares y amigos suyos para que asistiesen a los conciertos del intérprete ${ }^{73}$, como en los recitales que ofreció el 29 de octubre de 1958 en la Musikhalle (Laeiszhalle) Kleiner Saal de Hamburgo (Alemania) ${ }^{74}$, o el que llevó a cabo tiempo después en la Salle Gaveau ${ }^{75}$ de París, donde asistieron -entre otros- Doda Conrad o Francis Poulenc ${ }^{76}$.

En una de las cartas, Elsa Schünicke le propuso al músico contactar con el compositor francés enviándole una nota donde le recomendase escuchar la grabación que había realizado sobre el Concert Champêtre y que además, leyese

your charge is, so that we may plan our budget. I am enclosing a self-addressed envelope. Will you please answer at your earliest convenience. Sincerily yours. Rose N. Mende. Chairman". Carta de Miss Rose N. Mende a Rafael Puyana, Hartford, 12-4-1953.

${ }^{70}$ Jerry Dubis: "Bach 6 partitas, BWV 825-830", Fanfare, septiembre-octubre 2014, p. 102.

${ }^{71}$ Entrevista vía Skype realizada por M.Victoria Arjona a Álvaro Huertas, Bogotá (Colombia), 3 8-2017.

${ }^{72}$ Carta de Denise Restout a Rafael Puyana, 30-9-1958.

${ }^{73}$ Carta de Elsa Schunicke a Rafael Puyana, 1-10-1958.

${ }^{74}$ Programa de mano, 29-10-1958, Musikhalle (Laeisz-Halle), Kleiner Saal, Hamburgo. J.h D’anglebert (1628-1691), F. Couperin Le Grand (1668-1733), G. Picchi (circa 1620). M. Peerson (ca. 15801650). J. Bull (ca.16152-1628). William Byrd (1543-1623). D. Scarlatti (1685-1757). Partita a-moll/J. S. Bach (1685-1750).

${ }^{75}$ Carta de Elsa Schunicke a Rafael Puyana, s.f. Programa de mano, 6-11-1958, Salle Gaveau, París. 1. Chaconne de Galatée (M. de Lully) de Jean-Henry d'Anglebert (1628-1691), Musette de Taverny de François Couperin Le Grand (1668-1753), La Pantomime de François Couperin Le Grand (1668-1753); 2. Partita en La mineur (Fantasia, Allemande, Corrente, Sarabande, Burlesca, Scherzo, Gigue) de J. S. Bach (1685-1750). Entr'acte. 3. Ballo alla Polacha de Giovanni Picchi (c. 1620), The Fall of the Leafe de Martin Peerson (c. 15801650), Les Buffons John Bull (c. 1562-1628); 4. Passemezzo Antico di sei parti. Saltarello del ditto Passemezzo de Giovanni Picchi; 5. My Lady Carey's Dompe de autor anónimo inglés (s. XV), La volta de William Byrd (1543-1623), The king's Hunt de John Bull; 6. Deux Sonates (Mi majeur, La mineur) de Domenico Scarlatti (1685-1757).

${ }^{76}$ Carta de Denise Restout a Rafael Puyana, 25-10-1958. 
las críticas recibidas en prensa sobre los recitales realizados en Bogotá ${ }^{77}$. Muy obediente, este le escribió el día 3 de noviembre de 1958 para manifestarle su admiración por su obra para clave, lo mucho que la había trabajado y preguntarle si podía reunirse con él en París:

Querido señor, le escribo de parte de la Sra. Wanda Landowka, mi maestra. Estoy muy ansioso por conocerle. Daré un recital el próximo jueves, 6 de noviembre, en la Salle Gaveau y me sentiré particularmente honrado de que asista. He trabajado durante mucho tiempo su Concert Champêtre, que encuentro admirable y que he tocado con mucho éxito, especialmente en América. Tengo que partir al día siguiente de mi recital para ir a Bélgica e Inglaterra, pero volveré a París entre el 23 y 29 de noviembre y, si no está demasiado ocupado, me gustaría visitarle. Se lo ruego, estimado señor, que crea en mis sentimientos de profunda admiración ${ }^{78}$.

Por desgracia, aún no se ha encontrado ningún documento que aludiese a que ese encuentro se produjo.

La carrera de Rafael Puyana como concertista de clave despegó en 1957 y finalizó en $2005^{79}$, unos años antes de su muerte. Como se mencionaba anteriormente, su formación con Wanda Landowska terminó prácticamente un año antes de la muerte de la intérprete en $1959^{80}$ debido a la salud de Mamusia (como cariñosamente llamaban a la clavecinista polaca y que significa mamá en polaco ${ }^{81}$. La última vez que el intérprete vio a su estimada maestra fue en mayo de 1959, unos meses antes de su fallecimiento. Aquí se muestra una de las imágenes que se hicieron durante ese encuentro ${ }^{82}$ :

${ }^{77}$ Carta de Elsa Schunicke a Rafael Puyana, 10-10-1958.

${ }^{78}$ Carta de Rafael Puyana a Francis Poulenc, 3-11-1958, París. "Cher Monsieur, Je vous écris de la part de Madame Wanda Landowska, mon maître. Je serais extrêmement désireux de faire votre connaissance. Je donne un Récital jeudi prochain, 6 novembre, à la Salle Gaveau et je serais particulièrement honoré de vous voir y assister. J'ai travaillé longtemps votre Concert Champêtre que je trouve admirable et que j'ai déjà joué avec beaucoup de succès, notamment en Amérique. Je dois m'absenter le jour suivant mon Récital pour me rendre en Belgique et en Angleterre, mais je serais de retour à Paris entre le 23 et le 29 novembre et si vous n'être pas trop occupé, j’aimerais alors vous rendre visite. Je vous prie, Cher Monsieur, de vouloir bien croire à mes sentiments de profonde admiration".

${ }^{79}$ Hamilton Clive Únger: "Obituary: Rafael Puyana: Harpsichord virtuoso at the heart of the instrument's revival", The Guardian, 16-3-2013, p. 47.

80 "Rafael Puyana Obituario...".

${ }^{81}$ Carta de Denise Restout a Rafael Puyana, 30-9-1958.

82 "D. Marty: Vous l'avez suivie pratiquement jusqu'à sa mort? R. Puyana: Wanda était déjà très amoindrie la dernière fois que je l'ai vue, six mois avant de sa mort. On peut peut-être affirmer qu'une année avant sa disparition, elle ne créait plus. Vous voyez à quel point elle a été extraordinaire, car sa fin n'est venue qu'après ses quatre-vingts ans!". D. Marty, E. de Rubercy: "Le témoignage de Rafael Puyana...", pp. 5-6. 


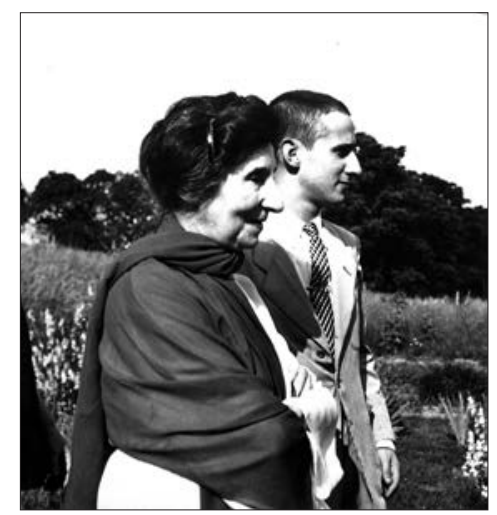

Wanda Landowska y Rafael Puyana en Lakeville, mayo 1959

La admiración de Rafael Puyana por su maestra perduró toda su vida. El intérprete incorporó a su biblioteca diversa documentación con el objetivo de conocer cómo fue evolucionando el pensamiento de Landowska, entre los que se encuentran los escritos que la clavecinista había realizado en libros y revistas, los programas o críticas de conciertos, las fotografias, una recopilación discográfica y diversas partituras e investigaciones realizadas. Cabe destacar el medallón de bronce con el perfil izquierdo de la clavecinista realizado por Boudier hacia 1906, el cartel que anunciaba el concierto del 14 de abril 1952 en el Town Hall de Nueva York, la primera página del Praeluduim XIV digitada por Landowska y una lista -cuya autoría se desconoce- que contiene todos los escritos que la maestra había realizado.

Cuando pedían al intérprete resumir todas las vivencias que había tenido con Landowska, Puyana solía decir que era un ejercicio muy complejo de realizar:

Mira, son tantas las cosas que me sugiere el nombre de Wanda Landowska que, en realidad, resulta imposible que, en una entrevista, yo pudiera resumir todo lo que, sobre el mismo vendría a mi imaginación. Te diré que, un día, una revista francesa me pidió que escribiera una impresión sobre el día en que conocí a Wanda Landowska. Me senté a escribir y durante un mes estuve trasladando al papel todo lo que yo tenía en mi mente sobre esta mujer. Al final, resultó un artículo larguísimo, lo cual me indicó que, no era este tema para escribir un artículo, sino que tenía material para escribir dos volúmenes. Tal era la riqueza de su personalidad el impacto que causaba y la maravillosa profundidad de su arte y de su persona.Yo tuve el privilegio de conocerla y te digo que, no puedo, sino hablar apasionadamente de ella, por esa fuerza extraordinaria de la naturaleza que irradiaba su persona ${ }^{83}$.

${ }^{83}$ César Alonso: "Hay muchas cosas que pasan por ser importantes y sin embargo jamás llegarán a ser representativas de nuestra época”, Ideal, 30-6-1983, p. 14. 
Al igual que su maestra, Puyana pretendía transmitir su pasión por la música antigua interpretándola desde el "sentido más humano" ", al mismo tiempo que sintió la "obligación moral de compartir con los demás lo que con tanta suerte" le había sido otorgado ${ }^{85}$ porque lo percibía como una gran responsabi$\operatorname{lidad}^{86}$. Fue así como el intérprete continuó la herencia musical de su maestra trasladándoselo a sus discípulos, entre los que se encuentran Genoveva Gálvez, María Teresa Chenlo, Christopher Hogwood, Sharon Gould, Martine Roche, Reynaldo Fernández Manzano, Mario Raskin, Álvaro Huertas, Maurizio Mackenzie, Trevor Pinnonck, Ursula Bartkiewicz, Elisabeth de la Porte, Pablo Cano, Ernesto Martínez o Martha Gómez.

\section{Conclusiones}

Rafael Puyana fue quien eligió ser discípulo de Landowska iniciando así un período de aprendizaje largo y una relación marcada por la admiración que el clavecinista expresó en diversas ocasiones a lo largo de su vida.

El joven intérprete se instaló en Lakeville -llegando a vivir más de seis añospara recibir clases particulares con la mencionada maestra mientras cursaba sus estudios en la Hartt Musical Foundation (Hartford), institución con la que colaboró como intérprete desde 1954-1956. Si bien en los primeros años de estudio con Landowska -a inicios de la década de los 50- el músico recibió una formación permanente, fue a partir de comenzar su trayectoria interpretativa (1955) y, sobre, todo de su debut en el Town Hall de Nueva York (1957), cuando cambió esta periodicidad. Según se refleja en la documentación consultada, la clavecinista tuvo un importante deterioro físico durante su último año de vida y no llegó a impartir clases, por lo que se puede decir que la etapa formativa entre maestra y discípulo osciló entre 1950-1958, y no entre 19511959 como apuntan todas las biografias. No obstante, y acorde al estado de investigación de su legado, es posible encontrar nuevos datos que modifiquen o amplíen la información aquí facilitada.

Durante este período, Landowska preparó a su discípulo mediante lecciones privadas, no solo para superar los exámenes de la escuela musical, sino también a iniciar su carrera en solitario como intérprete de clave, lo que incrementó su

84 “[...] Usted que fue el alumno de Wanda Landowska, ¿cuál fue su más importante consejo en cuanto al arte de tocar el clave? -Su más importante consejo era lo siguiente: cuando tocáis, tenéis siempre que dar vida, poesía y, sobre todo, claridad. Su más íntima intención era resucitar la música antigua en un sentido humano, y no un sentido puramente intelectual. Ella tocaba por el amor a la música, nunca por interés ajeno a la música. [...]". Casimir Ducados: "Rafael Puyana: Elegí el clave...", p. 4.

${ }^{85}$ José Antonio Lacárcel: "Rafael Puyana, el maestro colombiano: Para mí, la principal tarea es la de intérprete", Ideal, 28-6-1985, p. 15.

${ }^{86}$ Rafael Villegas: "Rafael Puyana: El clavicémbalo ha reconquistado su posición en la música antigua", Diario de Granada, 24-6-1983, p. 4. 
popularidad y varias propuestas de concierto. En mayo de 1959, Rafael Puyana visitó en Lakeville a su estimada maestra, convirtiéndose en la última vez que la vería. Sin embargo, el recuerdo y cariño hacia la gran clavecinista siempre permaneció en su memoria.

\section{Apéndice}

Listado de documentación perteneciente al Archivo Personal Rafael Puyana

\section{Epistolario}

Carta de Denise Restout a Rafael Puyana. 25-10-1954, AMF, Archivo Personal Rafael Puyana, caja 118 (b).

Carta de Denise Restout a Rafael Puyana, s.1., 25-10-1958, AMF, Archivo Personal Rafael Puyana, caja 118 (b).

Carta de Denise Restout a Rafael Puyana, 30-9-1958, s.l., AMF, Archivo Personal Rafael Puyana, caja 118 (b).

Carta de Elsa Schunicke a Rafael Puyana, 1-10-1958, s.l., AMF, Archivo Personal de Rafael Puyana, caja 118 (b).

Carta de Elsa Schunicke a Rafael Puyana, 10-10-1958, s.l., AMF, Archivo Personal de Rafael Puyana, caja 118 (b).

Carta de Elsa Schunicke a Rafael Puyana, s.f, s.l, AMF, Archivo Personal de Rafael Puyana, caja 118 (b).

Carta de Ernesto Puyana Uscategui, 23-3-1972, Montevideo, a señores del Instituto Interamericano de Musicología. AMF, Archivo Personal Rafael Puyana, caja 119. Carpeta Instituto Vikingo.

Carta de Miss Rose N. Mende a Rafael Puyana, 12-4-1953, Hartford, AMF, Archivo Personal Rafael Puyana, caja 16. Incluido en n..$^{\circ}$ R. 970.

Carta de Rafael Puyana a Francis Poulenc, 3-11-1958, París. AMF, Archivo Personal de Rafael Puyana, caja 118 (a).

Carta de Thomas W. Colley, 8-6-1950, Lakeville, a Rafael Puyana. AMF, Archivo Personal de Rafael Puyana, caja 103.

Carta de Wanda Landowska a Ernesto Puyana, 1-6-1953, Londres. AMF, Archivo Personal de Rafael Puyana, caja 95.

Carta de Wanda Landowska a la familia de Rafael Puyana, 31-12-1953, s.l. AMF, Archivo Personal de Rafael Puyana, caja 95.

Carta de Wanda Landowska a François Poulenc, 1-7-1953, Lakeville. BNFVM BOB24168, p. 663.

Carta de Wanda Landowska a Marc Pincherle, 6-5-1951, Lakeville. AMF, Archivo Personal Rafael Puyana, caja 95.

\section{Ilustraciones}

Ilustración 1: Instrucciones de evaluación y calificación obtenida por Rafael Puyana mientras estudia con Wanda Landowska (20-1-1955). AMF, Archivo Personal de Rafael Puyana, caja 118b.

Ilustración 2:Wanda Landowska y Rafael Puyana en Lakeville.AMF, Archivo Personal de Rafael Puyana, caja 95. Fotografias. 
Ilustración 3: Wanda Landowska y Rafael Puyana en Lakeville. Mayo 1959. AMF, Archivo Personal Rafael Puyana, caja 95. Fotografias.

\section{Otra documentación}

Carnet de usuario de Rafael Puyana, 5-12-1962, Bibliothèque nationale de France. BNF, s.n.

Carnet de usuario de Rafael Puyana, 25-12-1962, Archivo Personal de Rafael Puyana, caja 66. Adj. 2428.

Críticas de concierto, 16-10-1956, Teatro Colón (Bogotá) de Rafael Puyana. AMF, Archivo Personal Rafael Puyana, caja 100.Prensa.Sobre 7, (https://bit.ly/2kL6Eeh, consulta 5-10-2017).

Rafael Puyana: Wanda Landowska, pp. 56-58. AMF, Archivo Personal de Rafael Puyana, caja 95. Sobre con recortes de prensa.

\section{Partituras y ejercicios}

Joseph Haydn: Cadenzas: for the keyboard concerto in D major, opus 21: first and second movements. [Partitura], New York, Broude Brothers, 1960. AMF, Fondo Personal de Rafael Puyana. sig. C.11-3506.

Johan Sebastian Bach: Praeludium XIV.[Partitura], [Offenbach], Steingräber, [s.a].AMF, Fondo Personal de Rafael Puyana. sig. C.37-1544.

Wolfgang Amadeus Mozart: Cadenzas for the piano sonata in b-flat major, K. 333. [Partitura], New York, Broude Brothers, 1959. AMF, Fondo Personal de Rafael Puyana. sig. C.19-1908.

W. Landowska and R. Gerlin excercises for harpsichordists, ejercicios para trinos de R. P. [S.1.]: [s.n.], [s.a]. AMF, Fondo Personal de Rafael Puyana. sig. C.103-3790.

\section{Programas de mano}

Programa de mano, 19-5-1954, Hartt College of Music, Hartford. AMF, Archivo Personal de Rafael Puyana, caja 118 (b).

Programa de mano, 15-1-1956, Hartt Musical Foundation, Hartford. Library of Congress, box 86 , folder 4 .

Anuncio de concierto 1956 junio 7, Hartt Musical Foundation, Hartford. Rafael Puyana: Renacimiento del Clavicémbalo, Lecturas Dominicales, Bogotá, 21-10-1956, s.p. AMF, Archivo Personal de Rafael Puyana, caja 100.

Programa de mano, 23-10-1958, Opielt international Barock-Music, Berlín. Library of Congress, box 86, folder 1.

Programa de mano, 29-10-1958, Musikhalle (Laeisz-Halle), KleinerSaal, Hamburgo]. AMF, Archivo Personal de Rafael Puyana, caja 103.

Programa de mano, 6-11-1958, Salle Gaveau, París. AMF, Archivo Personal de Rafael Puyana, caja 118 (b).

\section{Revistas}

Daniel Marty: "Deux claviers pour Jean-Sebastien Bach", Une dame Nommee Wanda. Mairie de Saint-Leu-la-Fôret, [s.a], p. 11. AMF, Archivo Personal Rafael Puyana, caja 95. Revistas. 
Daniel Marty, Eryck de Rubercy: "Le témoignage de Rafael Puyana", Cahiers Wanda Landowska. Saint-Leu-la-Forêt, France, 3, 1982, pp. 2-7. AMF, Archivo Personal Rafael Puyana, caja 95. Cahier Wanda Landowska.

Denise Restout: "En souvenir de Ruggero Gerlin. Lakeville Février 1995”, Cahiers Wanda Landowska. Saint-Leu-la-Forêt, France, 13, 1995, p. 3. AMF, Archivo Personal Rafael Puyana, caja 95. Cahier Wanda Landowska.

Denise Restout: "Mamusia:Vignettes of Wanda Landowska. Recollections of the late great artist by a devoted companion of many years", High Fidelity. 10, 10, 1960, p. 43. AMF, Archivo Personal Rafael Puyana, caja 95. Revistas.

Denise Restout: "Pour le quatre-vingtième anniversaire de Gusta Goldschmidt", Cahiers Wanda Landowska. Saint-Leu-la-Forêt, France, 12, 1993, p. 6. AMF, Archivo Personal Rafael Puyana, caja 95. Cahier Wanda Landowska.

Robert Sabin: "Voyage of Discovery. Wanda Landowska has devoted 50 years to understanding "The Well-tempered clavier", Musical America, 15-02-1955, p. 3. AMF, Archivo Personal de Rafael Puyana, caja 100. Prensa. Sobre 7.

Ruggero Gerlin: "L'Ecole de Saint-Leu-la-Forèt", Revue Musicale de Suisse Romande, 32, 3, 1979, pp.16-17. AMF, Archivo Personal Rafael Puyana, caja 95. Revistas.

Recibido: 18-11-2018

Aceptado: 29-4-2019 